\title{
Change in judgment of direction of gaze after autokinetic perception
}

MichaEl J. Desisto AND SAMUEl C. McLAUghlin TUFTS UNIVERSITY

Subjects were allowed to perceive horizontal autokinesis for $30 \mathrm{sec}$ and then asked to look back to the starting point of the autokinetic $(A K)$ target. All Ss made a large eye movement in the direction opposite to that of $A K$ movement, indicating that after AK perception, a change in judgment of direction of gaze had occurred.

Many investigators have reported that after perception of autokinesis (illusory movement of a stationary point of light in an otherwise darkened room), there is a change in judgment of the direction of gaze. Bourdon (1902) found that if an AK target seemed to go $20^{\circ}$ to the right, the observer was clearly conscious of looking to the right, even though he was still looking straight ahead. If the $S$ shifted his gaze to the place he thought to be the starting point of the AK target, he was staring in a direction opposite to that of AK movement.

Carr (1910) and Adams (1912) also mentioned the illusion of pursuit movement which accompanies AK perception. The following quotation is from Adams: "The subject is often vividly conscious of pursuit movements he thinks he is making in following the light."

The purpose of the present experiment was to demonstrate the change in judgment of direction of gaze after AK perception by monitoring eye movements while Ss were asked to look back to the startpoint of the AK target.

\section{Subjects}

Five males and three females served as Ss. They did not have knowledge or previous experience in viewing autokinesis.

\section{Apparatus}

An AK target of 4 min of visual arc was in S's median plane at a distance of $1.74 \mathrm{~m}$.

Rotational position of the left eye was monitored by a detection system based on the principle described by Torok, Guilleman, \& Barnothy (1951), by Smith \& Warter (1960), and by Stark, Vossius, \& Young (1962). The principle uses the difference in matte reflectance between iris (dark) and sclera (white). A rectangle of light was imaged on the iris and sclera. A multiplier phototube detected brightness changes as more or less integrated light from the iris and sclera was reflected during an eye movement. The output of the multiplier phototube, after impedance conversion by a cathode follower, was led to a Sanborn (299) recorder.

By using an optical system of large aperture (5.5 $\mathrm{cm}$ ) and long focal length, the entire detection system

was kept $30 \mathrm{~cm}$ from the S's eye. The S's field of view was in excess of $30^{\circ}$ on each side of the primary direction of gaze.

\section{Procedure}

A bite plate bearing the S's dental impression was made and a patch put over the right eye. The detector was aligned for eye movement recording. The $S$ was asked to fixate the AK target and to make sure that he saw it clearly at all times. The $S$ was provided with a switch to depress if the AK target moved horizontally.

After the $\mathbf{S}$ had perceived horizontal autokinesis for $30 \mathrm{sec}$, he was suddenly asked to look back to the starting point of the AK target and then back to the AK target. During this period, eye position was monitored.

\section{Results}

Every S reported that he had seen the target clearly at all times, that he had tracked the target with his
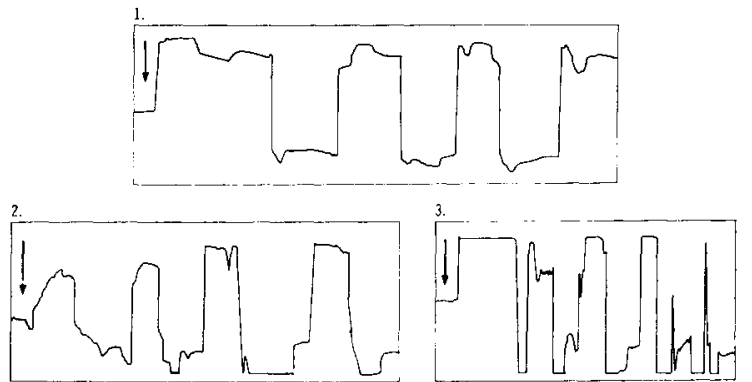
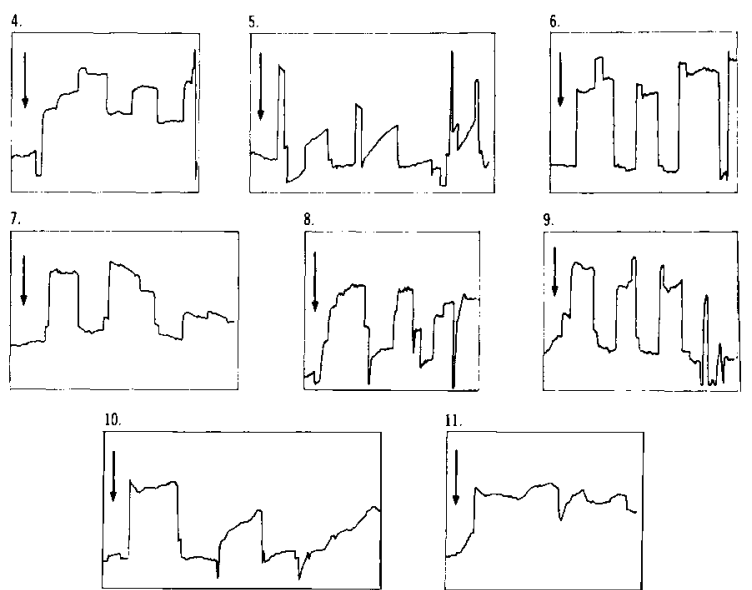

Fig. 1. Examples of eye movements made in response to the instruction "Look back where the target started from." The arrows mark when the instruction to look back was given. Each upward deflection is $S$ looking back where he thought the target began its movement. Each large downward deflection is $S$ looking at the target position after AK perception. 
eye, and that he noticed he had moved his eye when asked to look back to where the target started from.

Figure 1 shows examples of eye movements made in response to the instruction "Look back where the target started from." All Ss made a large eye movement when given this instruction. Also, as can be seen from Fig. 1, examples 1-10, this eye movement could be elicited a number of times by asking the $\mathrm{S}$ to look back and forth between the target position after AK perception and the target position before AK perception. However, these repeated eye movements were not always equal. Direction of 'look back" eye movements was opposite to the direction of perceived autokinesis.

No attempt was made to quantify these eye movements because linearity of the detection system over large eye movements was doubtful. However, it did seem that "look back" eye movements were as large as AK movement indicated by Ss' tracings.

Discussion

From Ss' verbal reports and "look back" eye movements one can conclude that after AK perception there is a change in the judgment of the direction of gaze, i.e., a discrepancy between where the eye really is and where the $S$ judges it to be. AK perception causes the $S$ to be conscious of making a pursuit movement in following the AK target when no pursuit movement is occurring at all.

It is interesting to note that a change in judgment of direction of gaze does not just occur after AK perception, but also occurs after a $S$ adapts to laterally displacing prisms (Helmholtz, 18672; McLaughlin \& Webster, 1967).

Given what we now know about the functioning of the oculomotor system, this change in judgment of direction of gaze is not surprising. Although Daniel (1946) found muscle spindles in the extraocular mus- cles, it appears that these muscle spindles do not effectively contribute to the position sense of the eye (Irvin \& Ludvigh, 1936; Brindley \& Merton, 1960). Furthermore, substantial doubt has arisen as to whether muscles and tendons contribute to the position sense of skeletal muscles, or whether this position sense is mediated solely by joint or articular sensitivity (Sarnoff \& Arrowhead, 1949; Gardner, 1950).

\section{References}

ADAMS, H. F. Autokinetic sensations. Psychol. Monogr., 1912, 14, 145.

BOURDON, B. La Perception visuelle de l'Espace, Paris, 1902.

BRINDLEY, G. S., \& MERTON, P. A. The absence of position sense in the human eye. J. Physiol, 1960, 153, 127-130.

CARR, H. A. The autokinetic sensation. Psychol. Rev., 1910, 17, 42-75.

DANIEL, P. Spiral nerve endings in extrinsic eye muscles of man. J. Anat., 1946, 80, 189.

von HELMHOLTZ, H. Handbuch der physiologischen optik. Leipzig: Leopold Voss, 1867.

IRVINE, S. R., \& LUDVIGH, E. Is ocular proprioceptive sense concerned in vision? Arch. Ophthal. 1936, 15, 1037.

McLAUGHLIN, S. C., \& WEBSTER, R. G. Changes in straight-ahead eye position during adaptation to wedge prisms. Percept. \& Psychophys., 1967, 2, 37-44.

SMITH, W. M., \& WARTER, P. J. Eye movement and stimulus movement: new photoelectric electromechanical system for recording and measuring tracking motions of the eye. J. Opt. Soc. Amer., 1960, $50,245-250$.

STARK, L., VOSSIUS, G., \& YOUNG, L. R. Predictive control of eye tracking movements. I.R.E. Trans. on Hum. Fact. in Electr., 1962, $52-56$.

TOROK, N., GUILleman, V., \& BARNOTHY, J. Photoelectric nystagmography. Ann. Otol. Rhinol and Laryngol, 1951, 60, 917-926. Notes

1. This research was supported in part by Research Grant GB-4196 from the National Science Foundation, by Contract MD-2714 with the U. S. Army Medical Research and Development Command, and by the National Aeronautics and Space Administration.

2. The first edition of Helmholtz' Handbuch is cited here to give an accurate date. The description of prism adaptation in the third edition $(1910 ; 1924$, p. $246 \mathrm{ff}$.) does not differ from that in the first edition (p. $601 \mathrm{ff}$.$) .$ 